\title{
Design, Synthesis, and Validation of an Effective, Reusable Silicon-Based Transfer Agent for Room-Temperature Pd- Catalyzed Cross-Coupling Reactions of Aryl and Heteroaryl Chlorides with Readily Available Aryl Lithium Reagents
}

\author{
Dionicio Martinez-Solorio ${ }^{\dagger}$, Bruno Melillo ${ }^{\dagger}$, Luis Sanchez ${ }^{\dagger} \S$, Yong Liang ${ }^{\ddagger}$, Erwin Lam ${ }^{\ddagger}, \mathrm{K}$. \\ N. Houk ${ }^{\ddagger},{ }^{*}$, and Amos B. Smith IIIt, ${ }^{\dagger}$ \\ †Department of Chemistry, University of Pennsylvania, Philadelphia, Pennsylvania 19104, United \\ States \\ $\neq$ Department of Chemistry and Biochemistry, University of California, Los Angeles, California \\ 90095, United States
}

\begin{abstract}
A reusable silicon-based transfer agent (1) has been designed, synthesized, and validated for effective room-temperature palladium-catalyzed cross-coupling reactions (CCRs) of aryl and heteroaryl chlorides with readily accessible aryl lithium reagents. The crystalline, bench-stable siloxane transfer agent (1) is easily prepared via a one-step protocol. Importantly, this "green" CCR protocol circumvents prefunctionalization, isolation of organometallic cross-coupling partners, and/or stoichiometric waste aside from LiCl. DFT calculations support a $\sigma$-bond metathesis mechanism during transmetalation and lead to insights on the importance of the $\mathrm{CF}_{3}$ groups.
\end{abstract}

\begin{abstract}
Transition-metal catalyzed cross-coupling reactions (CCRs) comprise indispensible tools in the organic chemists' arsenal of synthetic transformations. ${ }^{1}$ However, drawbacks of all traditional CCRs remain, including: (a) the synthesis, purification, and isolation of prefunctionalized organometallic cross-coupling partners, frequently accessed via the corresponding organolithium reagent (cf. Stille organotin, Suzuki organoboron, Negishi organozinc, and Hiyama/Denmark organosilicon reagents, Scheme 1A); (b) the frequent requirement of stoichiometric base/fluorides and elevated temperatures leading to functional group incompatibility; and most importantly (c) stoichiometric waste products. Pleasingly,
\end{abstract}

\footnotetext{
*Corresponding Authors. houk@chem.ucla.edu, smithab@sas.upenn.edu.

\$Present Address

Department of Chemistry, Niagara University, New York 14109, United States.

ASSOCIATED CONTENT

Supporting Information

The Supporting Information is available free of charge on the ACS Publications website at DOI: 10.1021/jacs.5b13260.

Crystallographic data (CIF)

Experimental details and data, and complete ref 20 (PDF)
}

The authors declare no competing financial interest. 
the Hiyama ${ }^{2,3} /$ Denmark $^{4}$ CCRs of organosilane reagents provide an environmentally friendly alternative; however, preconstruction of the organosilane is required.

The palladium-catalyzed CCRs of organolithium reagents pioneered by Murahashi, ${ }^{5}$ and recently extended by Feringa, ${ }^{6}$ comprise a highly atom-efficient process. ${ }^{7}$ Some limitations to the Murahashi/Feringa chemistry however remain (Scheme 1B): (a) slow addition of the organolithium nucleophile to limit formation of homocoupled products, a reaction avoided by the Nobel winning Negishi $\mathrm{ZnCl}_{2}$ protocol; $^{8}$ (b) reduced substrate scope due to competitive nucleophilic addition to reactive functionality on the electrophilic substrate; and (c) modest reactivity in some cases of the aryl chlorides, ideal electrophiles due to low cost and wide availability. ${ }^{9}$

Herein we report the design, synthesis, and validation of a reusable, bench-stable siliconbased transfer agent (1) that permits room-temperature Pd-catalyzed CCRs of aryl and heteroaryl chlorides with aryl lithium reagents (Scheme 1C).

In this regard, we recently reported Pd-catalyzed CCRs of organolithium reagents with aryl and alkenyl iodides exploiting a new class of recoverable/reusable silicon transfer agents ${ }^{10}$ inspired by the work of Tamao. ${ }^{11}$ However, attempts to extend their use to aryl chlorides (5, Scheme 2), led to incomplete conversions ( 60\%) and homocoupling. We therefore redesigned the transfer agent reasoning that incorporation of geminal $\mathrm{CF}_{3}$ groups at the benzylic position would have a two-fold effect: (a) enhanced electrophilicity at the silicon center of $\mathbf{1}$, now leading upon nucleophilic attack to an alkoxide intermediate of possible greater stability (3); and (b) facile regeneration of transfer agent $\mathbf{1}$ via the Thorpe-Ingold effect, thereby accelerating the transmetalation step eventually leading to cross-coupled products $(\mathbf{6}$, Scheme 2$)$.

Pleasingly, incorporation of isopropyl groups on silicon proved optimal in terms of physical properties, reactivity, and recoverability. Inspired by the work of Akiba ${ }^{12 a}$ and Britton, ${ }^{12 b}$ the synthesis of $\mathbf{1}$ was readily achieved from commercially available $\mathbf{7}$ via a one-step procedure (Scheme 3). Importantly, this reaction can be carried out with care $\left(\mathrm{H}_{2}\right.$ evolution) on multigram scale [see Supporting Information (SI)].

With transfer agent 1 in hand, we examined the cross-coupling of $\mathrm{PhLi}$ with 4-chloroanisole, which permits facile ${ }^{1} \mathrm{H}$ NMR analysis of the reaction mixture given the diagnostic methyl aryl ether resonance (Table 1). Our previous catalyst system $\left(\mathrm{PdCl}_{2}, \mathrm{CuI}\right.$, and dpca), employed in conjunction with earlier silicon transfer agents that proved effective in the reactions of aryl iodides, failed in the cross-coupling of 4-chloroanisole and $\mathrm{PhLi}$ (entry 1). Turning to the Penn/Merck High-Throughput Experimentation Center employing transfer agent $\mathbf{1}$, this same reaction was carried out in the presence of a variety of dialkylphosphino biaryl ligands and commercially available $\mathrm{Pd}(\mathrm{II})$ sources, ultimately leading to the identification of $\mathrm{Pd}(\mathrm{OAc})_{2}(5 \mathrm{~mol} \%)$ and XPhos $(10 \mathrm{~mol} \%)$ as a viable catalyst system (entries 2-4). Note: $\mathrm{Cu}$ is not required as employed with aryl iodides. ${ }^{10} \mathrm{By}$ increasing the catalyst loading to $10 \mathrm{~mol} \% \mathrm{Pd}(\mathrm{OAc})_{2}$ (20 mol\% XPhos), complete conversion was attained, employing only 1.3 equiv of $\mathrm{PhLi}$ (entry 5). Aiming to reduce catalyst loadings, we next turned to Buchwald's recently developed palladium precatalysts, which form 
monoligated $\operatorname{Pd}(0)$ species in situ when exposed to base. ${ }^{14}$ We reasoned that the alkoxide intermediate 3 would readily activate the precatalyst, thereby avoiding the need for an external base. Commercially available Buchwald G2 and G3 precatalysts led to incomplete conversions (entries 6 and 7). Pleasingly, however, when employing 3 mol \% precatalyst G4 ${ }^{14 \mathrm{c}}$ and 1.3 equiv of $\mathrm{PhLi}$, the reaction now proceeded to full conversion in $24 \mathrm{~h}$, at room temperature, to furnish $\mathbf{6 a}$ in near quantitative yield (98\%) with excellent recovery of $\mathbf{1}$ (84\%, entry 8). Importantly, 1 can be recovered and reused repeatedly without sacrificing reactivity. For example, recovered 1 from entry 8 was resubmitted to the same reaction to yield 6a (97\%). Notably, the catalyst loadings can be further decreased to $0.5 \mathrm{~mol} \%$ when employing only 1.1 equiv of $\mathrm{PhLi}$ by warming the reaction to $60{ }^{\circ} \mathrm{C}$ (entry 9). Of particular note, the undesired homocoupled product (8) was not detected in CCRs of aryl chlorides utilizing transfer agent 1. Consistent with Murahashi's observations, a control experiment in the absence of silicon transfer agent $\mathbf{1}$ resulted in the formation of homocoupling product $\mathbf{8}$ and incomplete consumption of 4-chloroanisole (entry 10). A second control experiment carried out in the absence of catalyst did not furnish the desired product (6a), with the benzyl alcohol arising from addition of phenyllithium to $\mathbf{1}$ as the only product (entry 11). In addition, we attempted to employ 1 in catalytic amount, unsurprisingly without success. ${ }^{10}$

With the optimized conditions, we next explored the scope of room-temperature Pdcatalyzed CCR of PhLi with various aryl-chloride coupling partners (Table 2). Both electron-rich and -deficient substrates led to excellent yields of the cross-coupled products (6b-n). Importantly, a variety of common functional groups were well tolerated on the electrophilic partner (i.e., esters, nitriles, azaheterocycles, fluorinated aromatics as well as quinolines); the reaction also proceeded in good yield with sterically encumbered aryl chlorides (6n, Table 2, and 9f, Table 3), albeit requiring higher temperature to reach full conversion. Also noteworthy, the reaction of all three regioisomers of chloropyridine (6km) proceeded efficiently. A case of interest is that of $\mathbf{6 e}$, which could not be separated chromatographically from 1 . We opted in this case for oxidative removal of the transfer agent, employing the Fleming-Tamao protocol. ${ }^{15}$ Importantly, however, in all other cases transfer agent 1 could be recovered in high yield via simple chromatography and reused without loss of reactivity or cross-contamination.

We next focused on the nucleophile scope. Pleasingly, heteroaryl and hindered aryl nucleophiles were all suitable to CCR, with the corresponding products (9a-f, Table 3) obtained in good yields. Hindered ortho-substituted aryl lithium reagents $(\mathbf{9 e})$ as well as electron-deficient aryllithium reagents $(\mathbf{9 f})$ reacted smoothly in $\mathrm{Et}_{2} \mathrm{O}$ with moderate heating $\left(45^{\circ} \mathrm{C}\right)$. We were particularly interested in the 2-pyridyl subunit given the prevalence of this structural unit in pharmaceuticals ${ }^{16}$ and natural products. ${ }^{17}$ We note that CCRs of 2-pyridyl moieties remain a challenging transformation. To this end, Burke et al. recently introduced bench-stable 2-pyridyl $N$-methyl-iminodiacetic acid (MIDA) boronates as viable crosscoupling partners to circumvent the unstable nature of 2-pyridyl boronic acids and esters. ${ }^{18}$ The synthesis of MIDA boronates, however, requires three steps. Pleasingly, use of siloxane transfer agent 1 permits direct cross-coupling of 2-lithiopyridine, thus mitigating the need for preconstruction of the 2-pyridyl MIDA boronates. The cross-coupling of 2-lithiopyridine 
with a variety or electron-rich and -deficient aryl chlorides is also illustrated in Table 3 (9ad).

Turning to the mechanism of this copper-free, Pd-catalyzed CCR, the question arises as to the nature of the reactive nucleophilic partner; that is, the ate-complex $\mathbf{1 1}$ or the open alkoxide 12 (Scheme 4). The former would imply direct transfer of $\mathrm{R}^{1}$ to the Pd-center with displacement of chloride, thus simultaneously resulting in the formation of the desired ligated diarylpalladium(II) $\mathbf{1 3}$, regeneration of transfer agent $\mathbf{1}$ and $\mathrm{LiCl}$, the latter the only stoichiometric waste. In contrast, reaction via 12 would require first the formation of a palladium(II) alkoxide, which would then either undergo $\sigma$-bond metathesis to give rise to the desired products or necessitate further activation (e.g., by attack on silicon of a second equivalent of alkoxide) in order to transfer the aryl group to the palladium center. ${ }^{19}$ The formation of a bimolecular ate-complex in this case seems counterintuitive given the considerable steric hindrance around the silicon center (cf. isopropyl groups) and the unfavorable entropic effect.

To gain an understanding of the mechanism, especially the effects of the geminal $\mathrm{CF}_{3}$ groups at the benzylic position of the transfer agent, we employed a computational approach. Scheme 5 summarizes our DFT (M06 with solvation) calculations on the processes involving the silicon-based transfer agents $\mathbf{A}-\mathbf{C F}_{\mathbf{3}}, \mathbf{A}-\mathbf{C H}_{\mathbf{3}}$, and $\mathbf{A}-\mathbf{H} \cdot{ }^{20}$ In the case of the new transfer agent $\mathbf{A}-\mathbf{C F}_{3}$, the nucleophilic attack of $\mathrm{PhLi}$ at the silicon center via transition-state $\mathbf{T S a}-\mathbf{C F}_{\mathbf{3}}$ requires an activation free energy of $12.7 \mathrm{kcal} / \mathrm{mol}$ in THF, leading to the open lithium alkoxide $\mathbf{B}-\mathbf{C F}_{\mathbf{3}}$. This step is exergonic by $6.1 \mathrm{kcal} / \mathrm{mol}$. Computational results show that the formation of the pentavalent siliconate $\mathbf{B}^{\prime}-\mathbf{C F}_{\mathbf{3}}$ and lithium cation from lithium alkoxide $\mathbf{B}-\mathbf{C F}_{\mathbf{3}}$ is endergonic by $10.3 \mathrm{kcal} / \mathrm{mol}$ in THF. This free energy is approximately the same as the activation energy for the transmetalation process from $\mathbf{B}-\mathbf{C F}_{\mathbf{3}}$ $(10.2 \mathrm{kcal} / \mathrm{mol}$, see later discussion). Therefore, subsequent transfer of the phenyl group from the ate-complex $\mathbf{B}^{\prime}-\mathbf{C F}_{\mathbf{3}}$ to the $\mathrm{Pd}(\mathrm{II})$-center is not likely. Alternatively, lithium alkoxide $\mathbf{B}-\mathbf{C F}_{\mathbf{3}}$ can form a four-membered complex $\mathbf{D}-\mathbf{C F}_{\mathbf{3}}$ with a simplified monoligated $\operatorname{Pd}(\mathrm{II})$ species C. ${ }^{14,21}$ This step is slightly endergonic by $1.9 \mathrm{kcal} / \mathrm{mol}$ in THF. After the dissociation of $\mathrm{LiCl}$, the palladium(II) alkoxide $\mathbf{E}-\mathbf{C F}_{\mathbf{3}}$ undergoes $\sigma$-bond metathesis via transition-state $\mathbf{T S b}-\mathbf{C F}_{\mathbf{3}}$, requiring an activation free energy of $9.3 \mathrm{kcal} / \mathrm{mol}$. From the resting state $\mathbf{B}-\mathbf{C F}_{\mathbf{3}}(-6.1 \mathrm{kcal} / \mathrm{mol})$ to transition-state $\mathbf{T S b}-\mathbf{C F}_{\mathbf{3}}(4.1 \mathrm{kcal} / \mathrm{mol})$, the overall barrier for the transfer of the phenyl group to the Pd(II)-center is $10.2 \mathrm{kcal} / \mathrm{mol}$, with generation of the diarylpalladium(II) species $\mathbf{F}$ exergonic by $22.4 \mathrm{kcal} / \mathrm{mol}$ in THF.

Comparison of the computational results of our model siloxane-based transfer agents A-H and $\mathbf{A}-\mathbf{C H}_{3}$ with those of $\mathbf{A}-\mathbf{C F}_{\mathbf{3}}$ (Scheme 5) clarifies the influence of the electronic and steric properties of the latter in the efficiency of CCRs. Without electron-withdrawing $\mathrm{CF}_{3}$ groups, the stability of lithium alkoxide $\mathbf{B}-\mathbf{C H}_{\mathbf{3}}$ is significantly decreased ( $3.5 \mathrm{vs}-6.1 \mathrm{kcal} /$ $\mathrm{mol})$, thus resulting in a much lower barrier for the regeneration of PhLi from the resting lithium alkoxide (7.7 vs $18.8 \mathrm{kcal} / \mathrm{mol}$, from $\mathbf{B}$ to TSa). Experimentally, this process leads to unreacted aryl chloride with no formation of the desired product. Absence of geminal $\mathrm{CF}_{3}$ groups at the a-position of oxygen in the four-membered complex D-H dramatically increases the stability ( $-20.7 \mathrm{vs}-4.2 \mathrm{kcal} / \mathrm{mol}$ ), making $\mathbf{D}-\mathbf{H}$ the resting state for the 
transmetalation step. This elevates the barrier for the transfer of phenyl group to the $\mathrm{Pd}(\mathrm{II})$ center $\left(16.4 \mathrm{kcal} / \mathrm{mol}\right.$ from $\mathbf{D}-\mathbf{H}$ to $\mathbf{T S b}-\mathbf{H}$ vs $10.2 \mathrm{kcal} / \mathrm{mol}$ from $\mathbf{B}-\mathbf{C F}_{\mathbf{3}}$ to $\left.\mathbf{T S b}-\mathbf{C F}_{\mathbf{3}}\right)$, decelerating the transmetalation process and the overall conversion.

In conclusion, a reusable, bench stable silicon-based transfer agent (1) has been designed, synthesized, and validated for effective room-temperature palladium-catalyzed CCRs of aryl and heteroaryl chlorides with readily accessible aryl lithium reagents. Noteworthy, the only stoichiometric waste product in this cross-coupling protocol is LiCl! Subsequent DFT calculations demonstrated that the preferred transmetalation step involves the lithium alkoxide, ${ }^{23}$ which leads to a palladium(II) alkoxide undergoing $\sigma$-bond metathesis. The geminal $\mathrm{CF}_{3}$ groups at the benzylic position of new transfer agent have two beneficial effects: (a) increased barrier for the regeneration of aryl lithium reagents, inhibiting the formation of homocoupling products; and (b) decreased barrier for transferring aryl groups to the Pd(II)-center, facilitating the conversion. Experimental studies exploring vinyl and other lithium reagents are ongoing.

\section{Supplementary Material}

Refer to Web version on PubMed Central for supplementary material.

\section{Acknowledgments}

Financial support was provided by the NIH (GM-29028) and the NSF (CHE-1361104). Calculations were performed on the XSEDE, supported by the NSF (OCI-1053575).

\section{REFERENCES}

1. (a) de Meijere, A.; Diederich, F., editors. Metal-catalyzed Cross-coupling Reactions. 2nd. Weinheim: Wiley-VCH; 2004. (b) Seechurn CCJ, Kitching MO, Colacot TJ, Snieckus V. Angew. Chem. Int. Ed. 2012; 51:5062.(c) Magano J, Dunetz JR. Chem. Rev. 2011; 111:2177. [PubMed: 21391570]

2. (a) Hatanaka Y, Hiyama T. J. Org. Chem. 1988; 53:918.(b) Hiyama T, Hatanaka T. Pure Appl. Chem. 1994; 66:1471.(c) Hiyama T. J. Organomet. Chem. 2002; 653:58.(d) Nakao Y, Hiyama T. Chem. Soc. Rev. 2011; 40:4893. [PubMed: 21755089]

3. For mechanistic insights also with rhodium catalyst see: Nakao Y, Chen J, Imanaka H, Hiyama T, Ichikawa Y, Duan W-L, Shintani R, Hayashi T. J. Am. Chem. Soc. 2007; 129:9137. [PubMed: 17602629]

4. Denmark SE, Choi JY. J. Am. Chem. Soc. 1999; 121:5821. For a review, see: Chang W-TT, Smith RC, Regens CS, Bailey AD, Werner NS, Denmark SE. Denmark SE. Organic Reactions. 2011; 75HobokenWiley:213-746.

5. (a) Murahashi S-I, Tanba Y, Yamamura M, Moritani I. Tetrahedron Lett. 1974; 15:3749.(b) Murahashi S-I. J. Organomet. Chem. 2002; 653:27.

6. (a) Giannerini M, Fañanás-Mastral M, Feringa BL. Nat. Chem. 2013; 5:667. [PubMed: 23881497] (b) Hornillos V, Giannerini M, Vila C, Fañanás-Mastral M, Feringa BL. Org. Lett. 2013; 15:5114. [PubMed: 24050648] (c) Vila C, Hornillos V, Giannerini M, Fañanás-Mastral M, Feringa BL. Chem. - Eur. J. 2014; 20:13078. [PubMed: 25214364]

7. Luisi, R.; Capriati, V., editors. Lithium Compounds in Organic Synthesis. Weinheim: Wiley-VCH; 2014.

8. (a) Negishi E, Baba S. J. Chem. Soc. Chem. Commun. 1976; (15):596.(b) Baba S, Negishi E. J. Am. Chem. Soc. 1976; 98:6729.

9. Grushin VV, Alper H. Chem. Rev. 1994; 94:1047. 
10. (a) Smith AB III, Hoye AT, Martinez-Solorio D, Kim W, Tong R. J. Am. Chem. Soc. 2012; 134:4533. [PubMed: 22352347] (b) Martinez-Solorio D, Hoye AT, Nguyen MH, Smith AB III. Org. Lett. 2013; 15:2454. [PubMed: 23627729]

11. Son E-C, Tsuji H, Saeki T, Tamao K. Bull. Chem. Soc. Jpn. 2006; 79:492.

12. (a) Yamamoto Y, Takeda Y, Akiba K. Tetrahedron Lett. 1989; 30:725.(b) Cho I, Meimetis L, Britton R. Org. Lett. 2009; 11:1903. [PubMed: 19326895]

13. Image of crystal structure of 1 generated using: Legault CY. CYL view, 1.0b. 2009Quebec, CanadaUniversité de Sherbrooke(http://www.cylview.org)

14. (a) Bruno NC, Tudge MT, Buchwald SL. Chem. Sci. 2013; 4:916. [PubMed: 23667737] (b) Bruno NC, Buchwald SL. Org. Lett. 2013; 15:2876. [PubMed: 23675976] (c) Bruno NC, Niljianskul N, Buchwald SL. J. Org. Chem. 2014; 79:4161. [PubMed: 24724692]

15. (a) Tamao K, Ishida N, Tanaka T, Kumada M. Organometallics. 1983; 2:1694.(b) Fleming I, Henning R, Plaut H. J. Chem. Soc. Chem. Commun. 1984; (1):29.

16. DeGoey DA, Grampovnik DJ, Flentge CA, Flosi WJ, Chen H-J, Yeung CM, Randolph JT, Klein LL, Dekhtyar T, Colletti L, Marsh KC, Stoll V, Mamo M, Morfitt DC, Nguyen B, Schmidt JM, Swanson SJ, Mo H, Kati WM, Molla A, Kempf DJ. J. Med. Chem. 2009; 52:2571. [PubMed: 19323562]

17. Nicolaou KC, Scarpelli R, Bollbuck B, Werschkun B, Pereira MMA, Wartmann M, Altmann KH, Zaharevitz D, Gussio R, Giannakakou P. Chem. Biol. 2000; 7:593. [PubMed: 11048950]

18. (a) Knapp DM, Gillis EP, Burke MD. J. Am. Chem. Soc. 2009; 131:6961. [PubMed: 19405470]

(b) Dick GR, Knapp DM, Gillis EP, Burke MD. Org. Lett. 2010; 12:2314. [PubMed: 20465293]

(c) Dick GR, Woerly EM, Burke MD. Angew. Chem. Int. Ed. 2012; 51:2667.

19. Tymonko SA, Smith RC, Ambrosi A, Ober MH, Wang H, Denmark SE. J. Am. Chem. Soc. 2015; 137:6200. [PubMed: 25945516]

20. All calculations were performed with: Gaussian 09, Revision D.01; Gaussian Inc.: Wallingford, CT, 2013; see the SI.

21. For related computational studies, see: Barder TE, Biscoe MR, Buchwald SL. Organometallics. 2007; 26:2183. Bonney KJ, Schoenebeck F. Chem. Soc. Rev. 2014; 43:6609. [PubMed: 24759955] and references therein.

22. For structures of key intermediates and transition states, see the SI

23. ${ }^{29} \mathrm{Si}$ NMR experiments confirmed quantitative formation of alkoxide intermediate $\mathbf{1 2}(\delta-9.13$ $\mathrm{ppm}$ ) upon addition of PhLi to 1 ( $\delta 34.81 \mathrm{ppm})$. See Supporting Information. 
A. Traditional Cross-Coupling Reactions (CCRs)

- prefunctionalization necessary

- stoichiometric metal waste

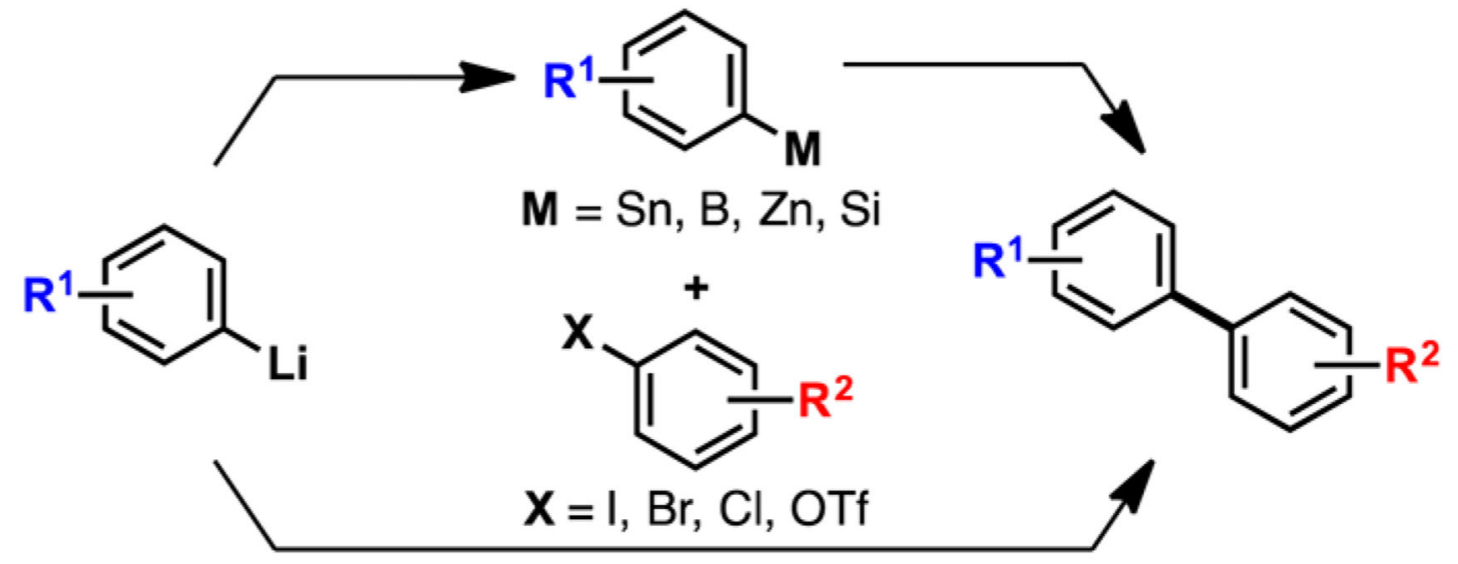

B. Previous work: Organolithium Pd-Catalyzed CCRs

- slow addition required

- narrow substrate scope

\section{This work:}<smiles>[R][R]1ccc(Cl)cc1</smiles><smiles>[R][R]1ccc(Cl)cc1</smiles><smiles>[R][X]1ccc(-c2ccc([R])cc2)cc1</smiles>

Scheme 1.

Approaches Towards Cross-Coupling 


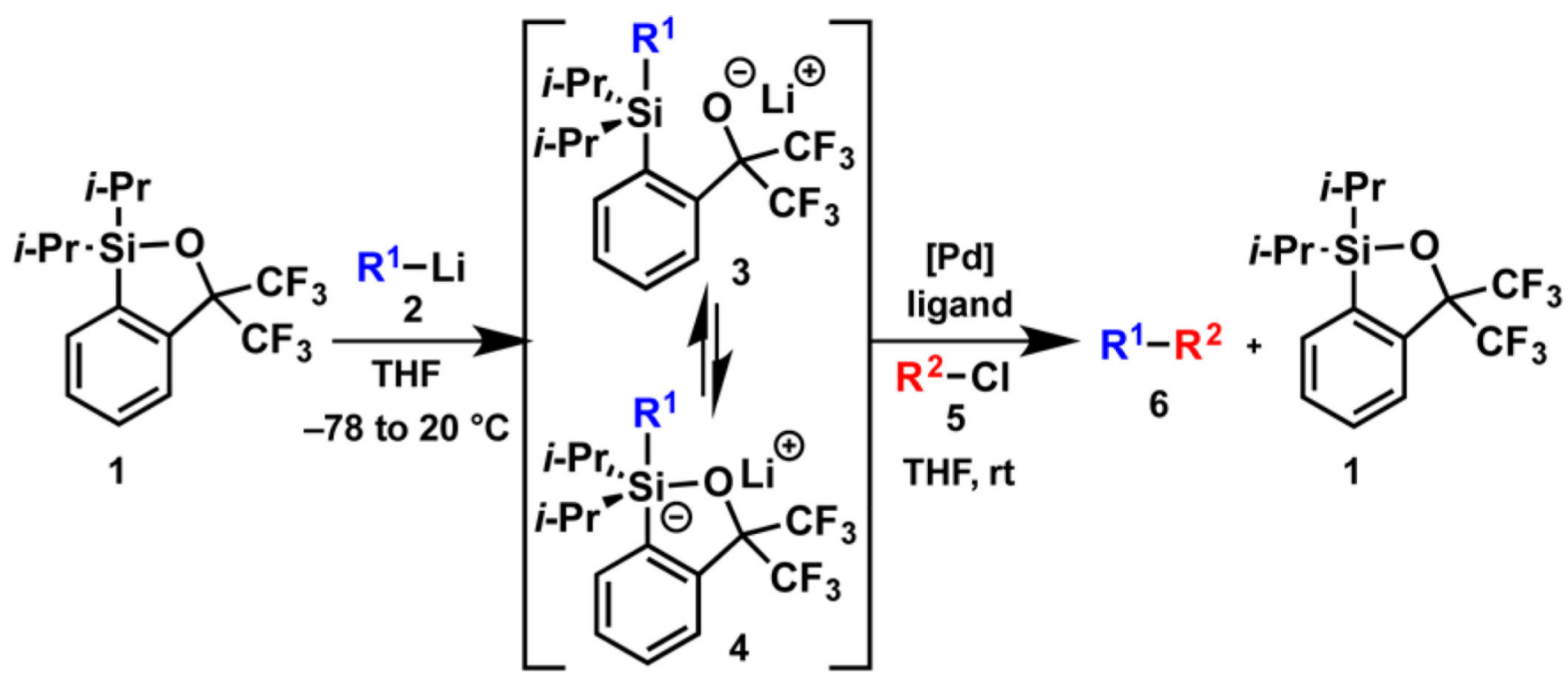

Scheme 2.

Design of a Transfer Agent for CCRs of Aryl Chlorides 

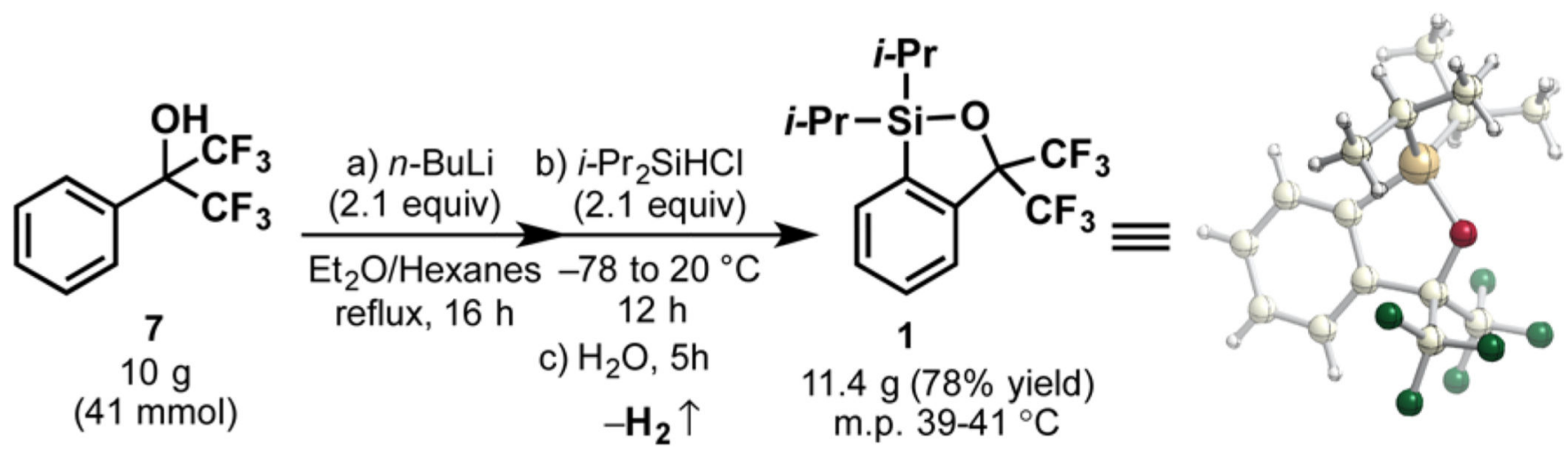

Scheme 3.

Synthesis of Bistrifluoromethyl Transfer Agent ${ }^{13}$ 


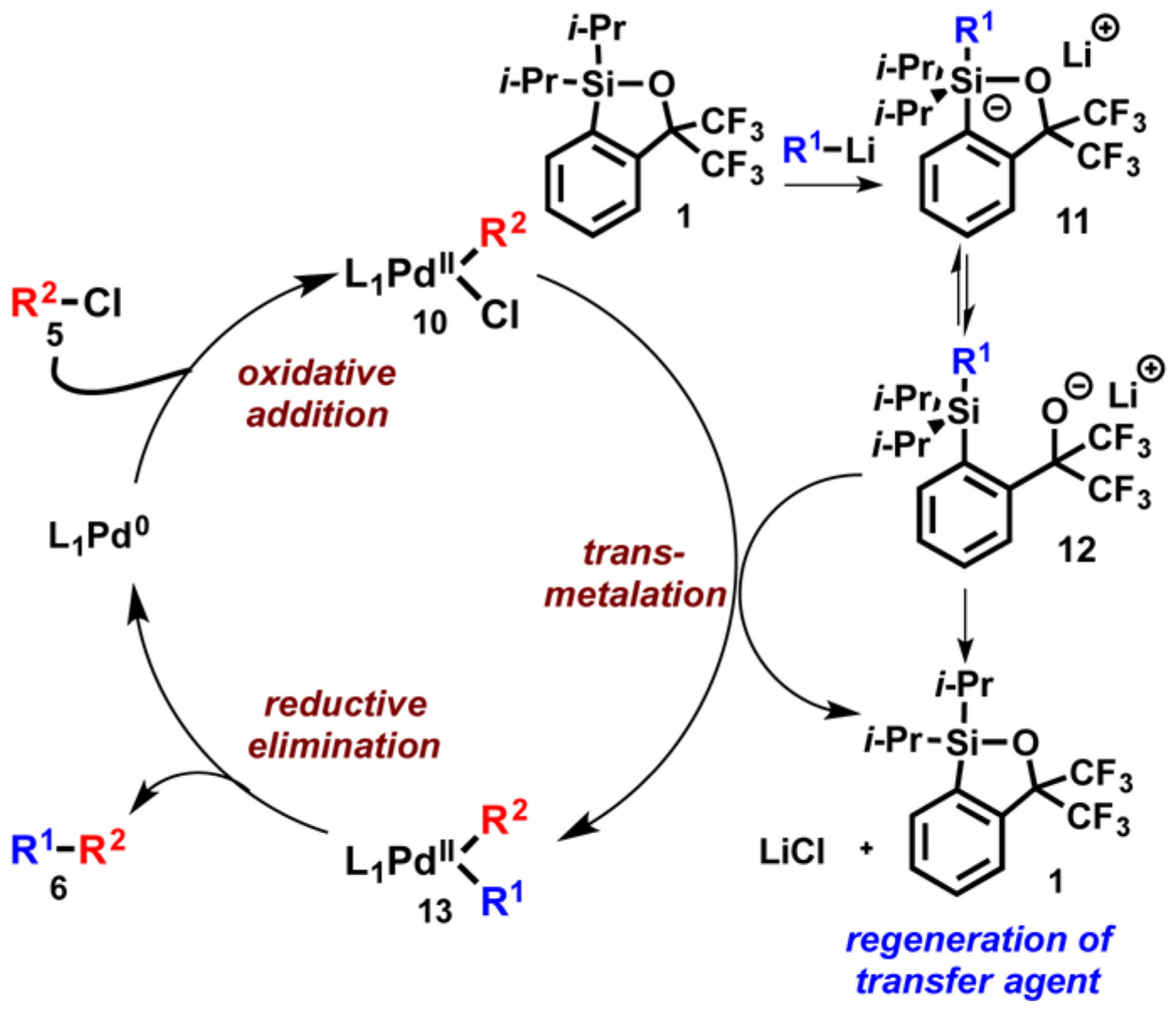

Scheme 4.

Proposed Catalytic Cycle 
<smiles>[R]C1([R])O[Si]([PH])([PH])c2ccccc21</smiles>

A

$$
\begin{array}{cll}
\Delta \mathrm{G}_{\text {THF }} & \mathrm{R}=\mathrm{CF}_{3}(0.0) \\
(\mathrm{kcal} / \mathrm{mol}) & \mathrm{R}=\mathrm{CH}_{3}(0.0) \\
& \mathrm{R}=\mathrm{H} \quad(0.0)
\end{array}
$$

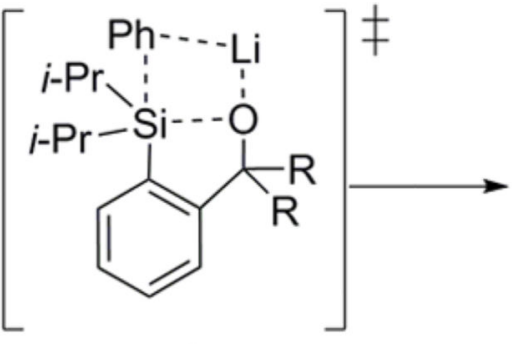

TSa

(12.7)

(11.2)

(10.7)

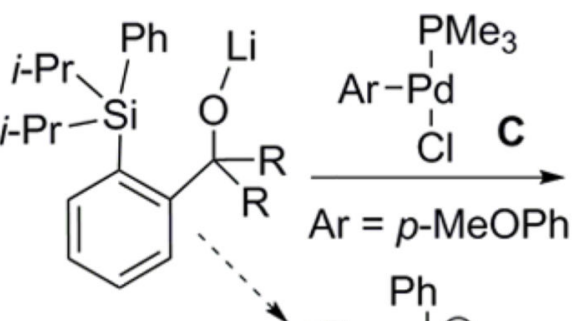

B

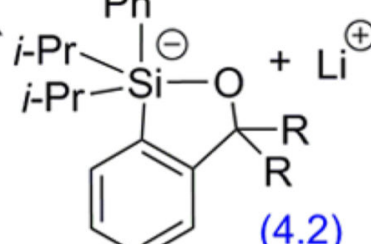

B' (15.4)

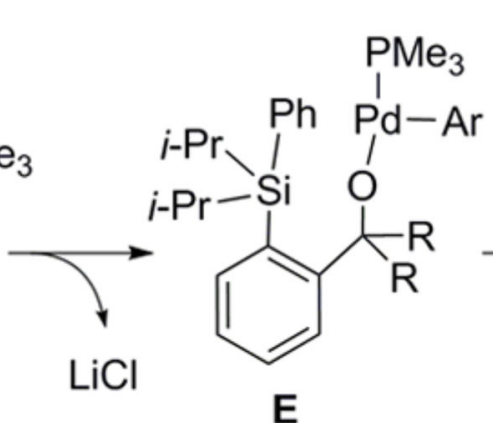

$(-5.2)$

$(-2.6)$

$(-8.5)$

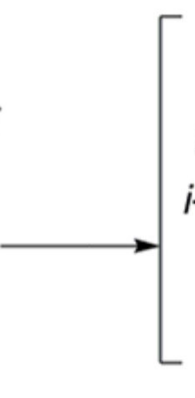

$(-4.2)$

$(-8.4)$

$(-20.7)$

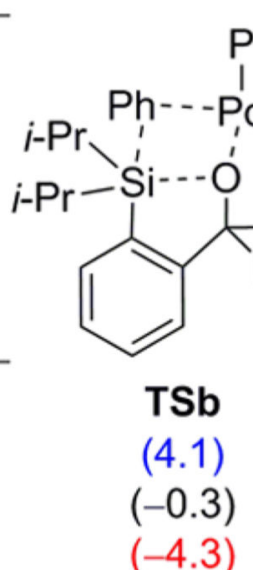

TSb

$(-0.3)$

$(-4.3)$

Scheme 5.

DFT Study $^{22}$ 


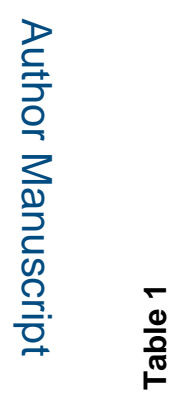

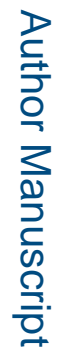

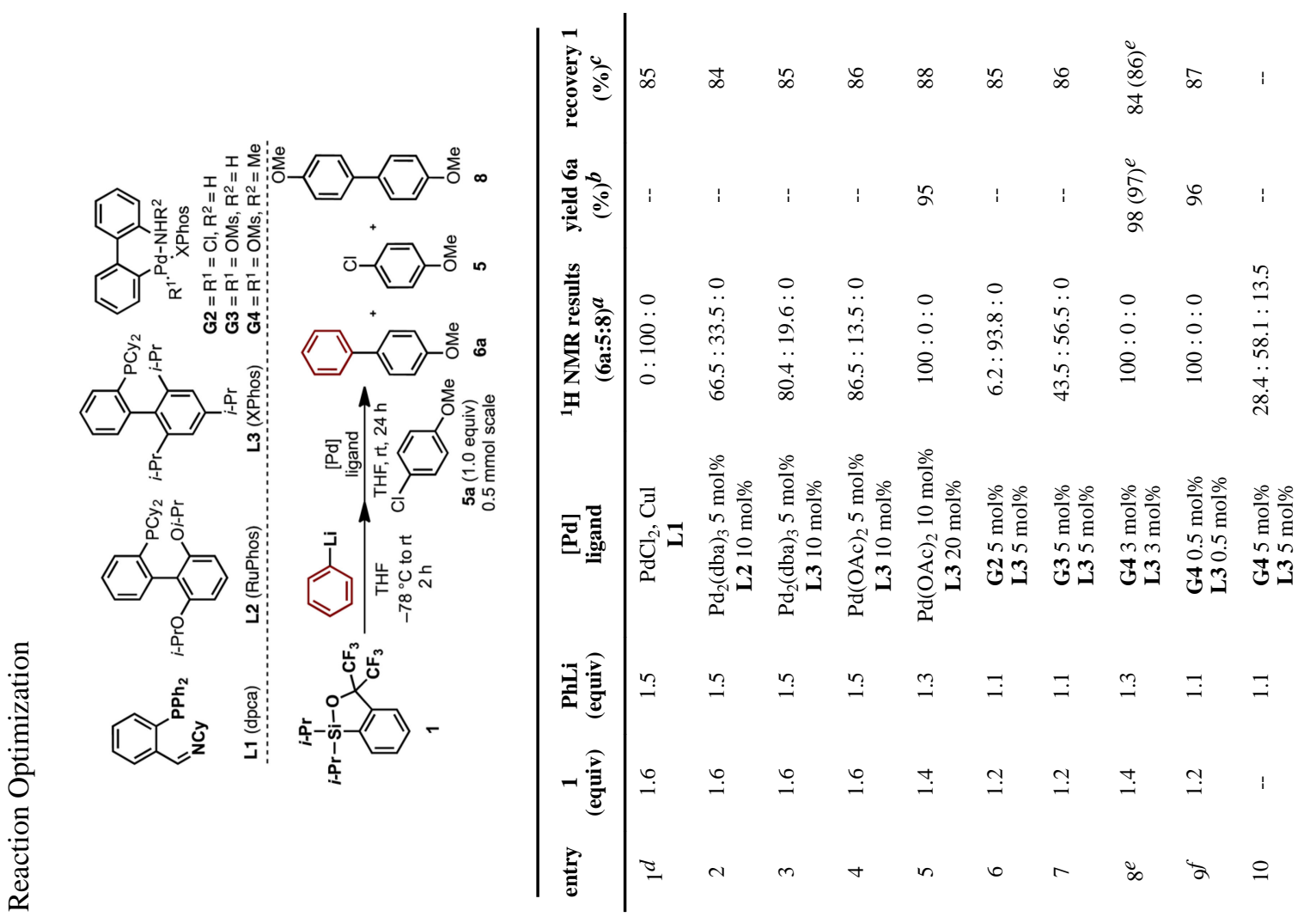

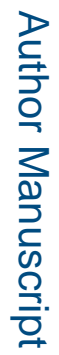

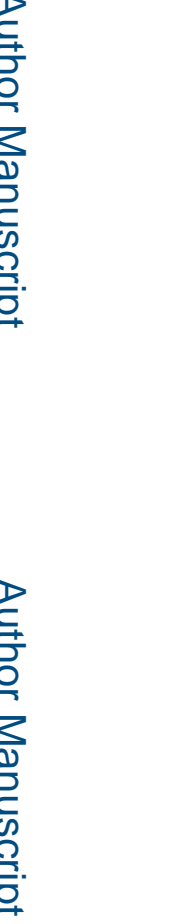




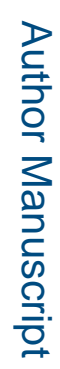

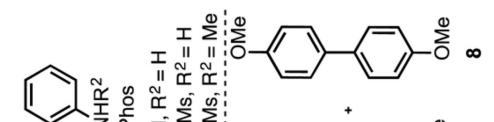

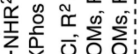
(1)
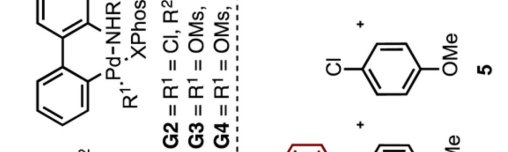

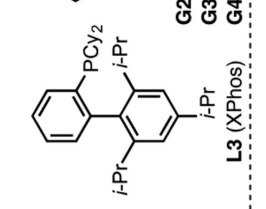

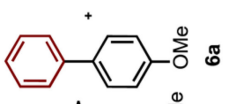

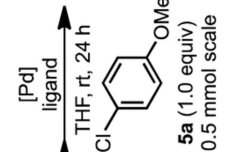

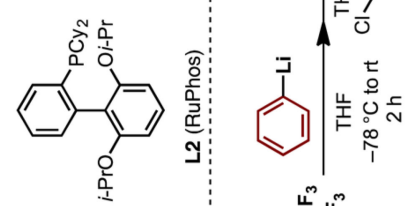

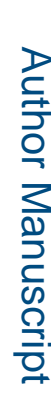

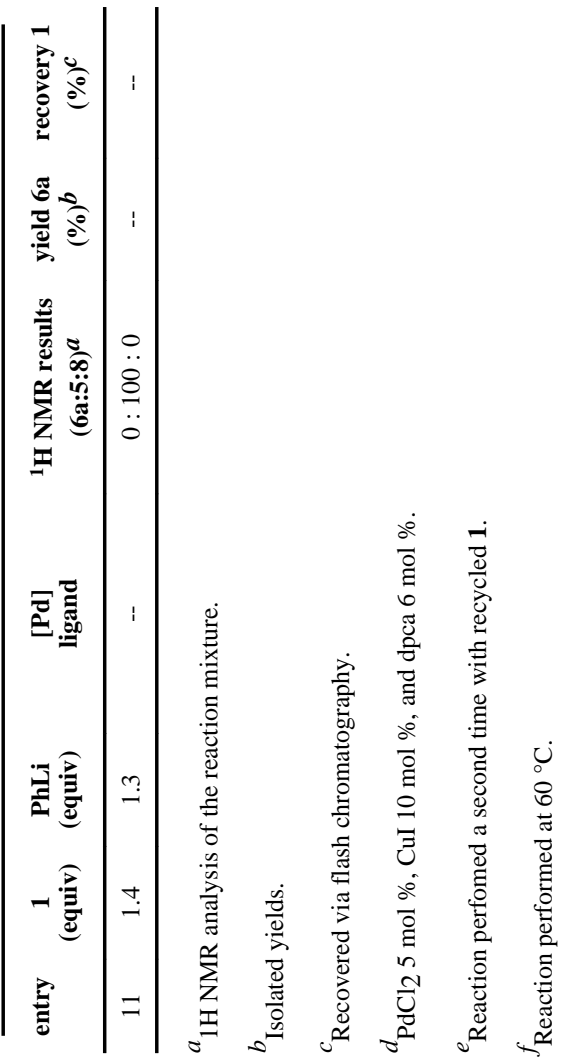


Table 2

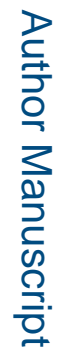

Substrate Scope: Aryl Chlorides ${ }^{a}$

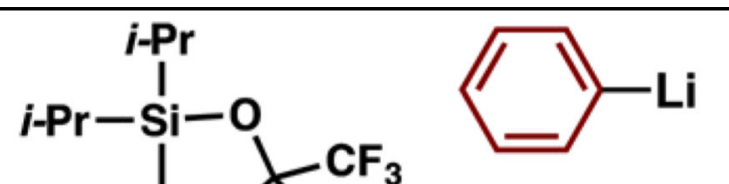<smiles>Cc1ccccc1C(C)(C(F)(F)F)C(F)(F)F</smiles>

1

1.4 equiv $-78^{\circ} \mathrm{C}$ to rt, $2 \mathrm{~h}$

\section{3 equiv}

G4 precat. (1-5 mol\%)

XPhos (1-5 mol\%)

THF, rt, 3 - 24 h

$\mathrm{Ar}-\mathrm{Cl}$

$0.5 \mathrm{mmol}$ scale

(1.0 equiv)

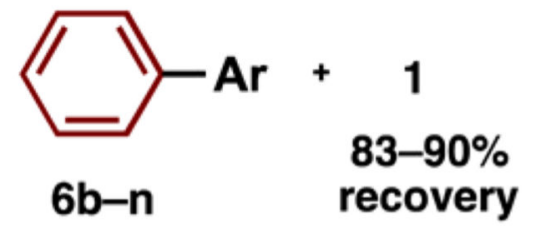

recovery

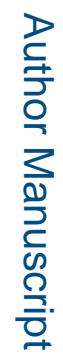

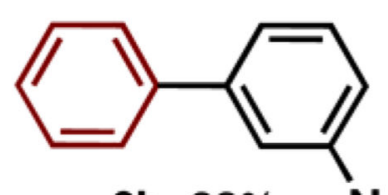

6b: $99 \%$<smiles>C1CNC1</smiles>

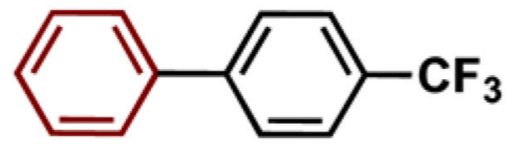

6e: $88 \%{ }^{c}$

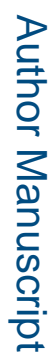

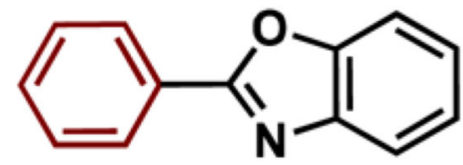

6h: $82 \%$

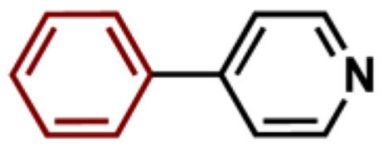

6k: $91 \%{ }^{b}$

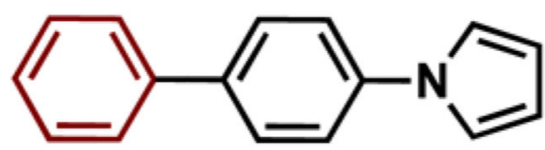

6c: $97 \%$

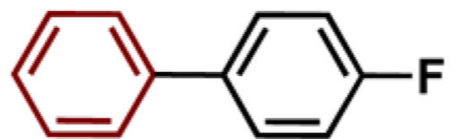

6f: $87 \%$

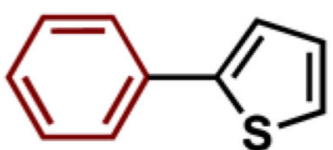

6d: $82 \%$

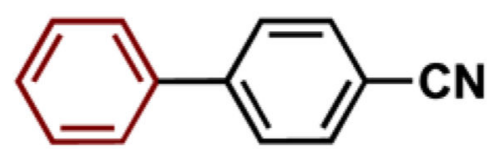

$6 \mathrm{~g}: 78 \%^{b}$

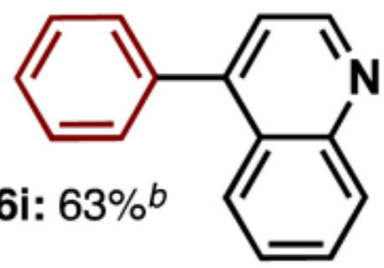

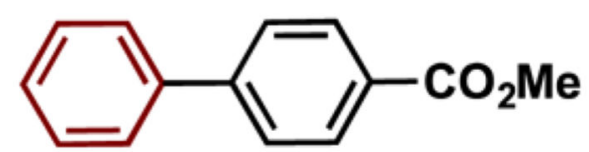

6j: $81 \%^{b}$

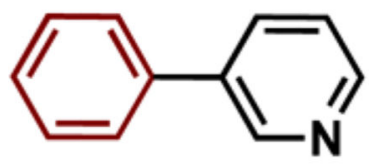

6I: $95 \%$

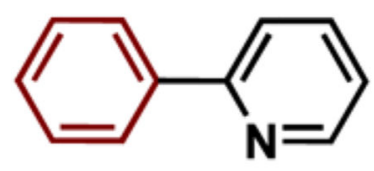

6m: $92 \%$

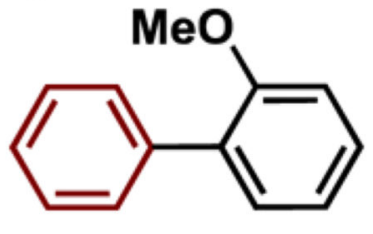

6n: $98 \%{ }^{d}$

$a_{\text {Isolated yields. }}$

${ }^{b} \mathrm{Pd}(\mathrm{OAc})_{2} 10 \mathrm{~mol} \%$, XPhos $20 \mathrm{~mol} \%$.

${ }^{c}$ After Fleming-Tamao oxidation.

$d_{70{ }^{\circ} \mathrm{C}}$ 
Table 3

Substrate Scope: Organolithium Reagents ${ }^{a}$

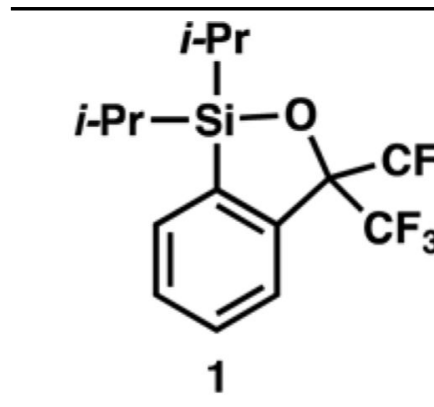

1.4 equiv

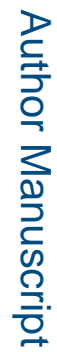

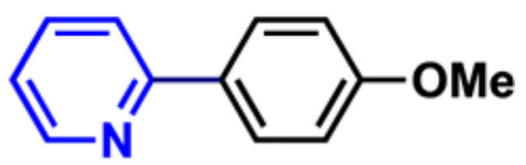

9a: $72 \%$

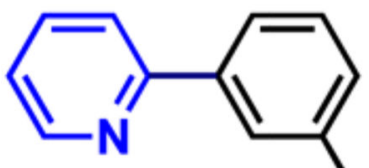

9d: $73 \%$

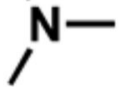<smiles>FC(F)(F)c1ccc(-c2ccccn2)cc1</smiles>

9b: $82 \%$

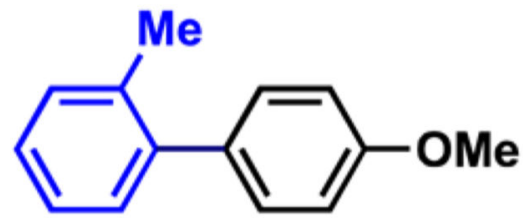

9e: $87 \%^{b}$<smiles>c1ccc(-c2nc3ccccc3o2)nc1</smiles>

9c: $52 \%$<smiles>Cc1ccncc1-c1ccc(C(F)(F)F)cc1</smiles>

9f: $81 \%^{b}$

$a_{\text {Isolated yields. }}$

${ }^{b}$ Cross-coupling step performed in Et2 $\mathrm{O}$ at $45^{\circ} \mathrm{C}$. 